\title{
An epidemiological study of injury in a rural community in Bangladesh
}

\author{
Chowdhury $\mathrm{SH}^{1}$, Karim $\mathrm{MN}^{2}$, Rahman $\mathrm{MR}^{3}$, FAiz MA ${ }^{4}$, Ahmed F ${ }^{5}$, Selim $\mathrm{S}^{6}$ \\ 1. Consultant, Sorkai Kormocari Hospital, Dhaka, 2. National Consultant (CHP), WHO country office \\ Bangladesh, 3. Department of Medicine, Shaheed Suhrawardy Medical College, Dhaka, 4. Department of \\ Medicine (Retd), Sir Salimullah Medical College, Dhaka, 5. MO, NICVD, Dhaka, 6. Department of \\ Endocrinology \& Metabolism, BSMMU, Shahbag, Dhaka. \\ Email: selimshahjada@gmail.com
}

\begin{abstract}
Injuries are a focus of public health practice because they pose a serious health threat, occur frequently and are preventable. The evidence regarding injury, its contributing factor and its consequence in rural population of Bangladesh is scarce. Present study aimed to assess the epidemiology of injury in a rural area. The study was conducted in the 'Bairag' Union of Anwara upazilla in Chittagong district of Bangladesh. Data of 6256 individuals were collected from 1016 households. Three structured and standardized questionnaires were used for data collection. The questionnaires were pretested and validated prior to final survey. Severity of injury was assessed based on the number of days with restricted activity and consequences of injury were considered as a measure of severity of injury. A total of 6 people died due to injury in last one year in the survey, the death tolls to $0.096 \%$ (95\% CI $0.037 \%-0.199 \%)$. A total of 392 experienced an injury that at least hampered one day's routine activity. Crude prevalence of injury over last one year is calculated to be $6.27 \%$ (95\% CI 5.69\%$6.89 \%$ ). Of injured subject's majority $(77.2 \%)$ were aged between 10 to 59 years, $73 \%$ were male, $55.6 \%$ were of lower class and among them $7.9 \%$ suffered multiple injuries. More than $80 \%$ of the incident leading to injury happened during the day, (8 am to $6 \mathrm{pm}$ ). Daytime injury mostly occurs in afternoon. The mechanism of injury of $30 \%$ subjects were road accident, of $29.5 \%$ subjects was slip, trip or fall. In $17.9 \%$ victims' mechanism of injury was collision with a person or object. Around $10 \%$ had deep cut, $1.4 \%$ had superficial cut, and $3.3 \%$ patient had burn through contact with heat. Among the injured only $19.2 \%$ escaped any physical consequence, $27.2 \%$ suffered from decrease in work capacity, $48.1 \%$ developed temporary disability, $3.8 \%$ developed permanent disability, and $1.2 \%$ suffered disfiguration.
\end{abstract}

\section{Introduction}

Injury is physical damage due to the transfer of energy. Injury occurs when the amount of energy transfer exeeds the host organism's threshold tolerance. The type of energy can be mechanical, thermal, chemical, electrical, radiation or the absence of essentials such as oxygen (asphyxiation, drowning) or heat (hypothermia). Mechanical energy is the most frequent cause of injury. ${ }^{1}$ Injury is becoming major public health problem worldwide. ${ }^{1}$ According to recent estimates, each year over 5 million people around the world die as a result of an injury. It is estimated that by 2020 , injury would be the prime contributor in the total disease burden. ${ }^{2}$ National Sample Survey Organization of neighboring India, which share almost similar rural socioeconomic profile as Bangladesh found that the poor households have to spend a high amount for treatment of severe injuries than other diseases. ${ }^{3}$ Injuries disproportionately affect the poor in low and middle income countries. ${ }^{4}$ In Bangladesh percent
GDP loss from road traffic injuries is 1.6. In China, it is estimated that road traffic injuries cost $\$ 12.5$ billion, which is four times the total public health budget. $^{5}$

Many injuries are linked to social, environmental, cultural and biological issues in causation; recognized as man-made and behavior linked disorders and linked to socio-demographic transition. Like any other health problem, injuries also have a definitive causative pattern and mechanism in terms of agent (product/vehicle), host (human beings) and environmental (roads, homes, workplaces) factors along with system-related issues. A precise understanding of this mechanism is crucial to develop and implement mechanisms for prevention and control of injuries.

Majority of the data on injury available in Bangladesh are generated from hospital and police records. Community-based injury surveys have one overriding advantage over hospital-based surveillance methods in that they capture injuries that fail to reach hospitals, i.e. those injury deaths 
occurring in the community, injuries that are treated outside the formal health sector and minor injuries that do not necessarily require hospital attention. There are very few population based studies to understand the various causes of injuries in predominant rural population of developing country like Bangladesh. ${ }^{4}$ Hence, the objective of the present rural community based study was to determine the prevalence of all injuries, its nature, outcome and sources of treatment in a rural population. Consequently, we report results from a rural survey, conducted in February 2010.

\section{Material and Methods}

Setting: The study was conducted in the 'Bairag' Union of Anwara upazilla in Chittagong district of Bangladesh. A community based cross sectional study was conducted between January to june 2011 . The study place is about 20 kilometer from the Chittagong port city and represents a rural area in Bangladesh. Data of 6256 individuals were collected from 1016 households. Heads of all households or a responsible person in absence of household heads were interviewed. Three structured and standardized questionnaires were used for data collection. The questionnaires were developed by three consultative meetings comprising experts in the field of injury. One of the three questionnaires was a screening form used to identify whether a household member had an injury in the past one year. Along with injury information, socio-demographic variables were also inquired. Second of them was used to inquire about type, cause, place, activity at the time of injury and circumstances in which the injury occurred as well as consequences of injury in terms of type and length of disability, health seeking behavior etc. Subjects who have suffered injury within the past 12 months preceding the time of study were interviewed. Third one was used to inquire about injury that resulted in death. Data regarding the injury related deaths was collected for the past one year. The questionnaire was pretested and validated prior to final survey. Based on Internal Consistency coefficient (Cronbach's alpha 0.852), the questionnaire was found to be consistently reliable. Spearman-Brown stepped-up reliability coefficient showed no significant differences between the two tests conducted at an interval of four weeks. The inter-rater reliability $(k)$ for the raters was found to be $0.874 \pm 0.071(\mathrm{p}<0.001)$ for Severity of injury, $0.823 \pm 0.068 \quad(\mathrm{p}<0.001)$ for Physical consequences, $0.725 \pm 0.100(\mathrm{p}<0.001)$ for Occupational consequences, $0.681 \quad \pm 0.101$ $(\mathrm{p}<0.001)$ for Social consequences and $0.851 \pm 0.063(\mathrm{p}<0.001)$ for Fiscal consequences.
The raters were found to be quite stable in grading the injury severity, and consequences.

Data Analysis: Epidemiological aspect of injury including its annual incidence and consequences was assessed. Data were analyzed by using STATA® 10 I/C and SPSS $® 16.0$.

Measures of Injury: For ascertaining the injury, history of injury provided by the household heads about his/her or of any of the family member was considered. Number of injury suffered by an individual was recorded based on the answer following the question 'during the past 12 months, how many times were you/or any of your family members injured?', and health seeking behavior was recorded based on the answer to the question "had you/or family member been treated by a doctor or nurse for the injury?" Socio economic status was assessed at the household level by using income of household, condition of house, possession of selected essential and luxury article and appliances. Severity of injury was assessed based on the number of days with restricted activity (disability days) and consequences of injury was considered as a measure of severity of injury. Grade I referred to injury that resulted with 1 or more days missed from usual activities; Grade II referred to injury that required two or more of the following treatments: placement of a cast, stitches, use of crutches and surgery or injury that resulted in overnight hospitalization; Grade III referred to loss of limbs, organ or any part of body that results in permanent disability and compromised quality of life and death as a consequence of injury was considered as grade IV.

\section{Result}

Data of a total of 6256 individuals were collected from 1016 households. Person per household was 6.154 (6.003 - 6.308) and male to female ratio as 100: 93. Of 6256 individuals 392 experienced an injury in last one year that at least hampered one day's routine activity. Crude prevalence of injury over last one year is calculated to be $6.3 \%$ (95\% CI $5.7,6.9)$. Total six people died due to injury in last one year in the survey area, the death tolls to $0.096 \%$ (95\% CI 0.037, 0.199). Among the people who suffered injury majority were between age ranges of 10 years to 59 years. Around three fourth of them $(73 \%)$ were male. Similar to the distribution of the catchment population, majority $(55.6 \%)$ were of lower class, $32.4 \%$ were of lower middle class, $8.7 \%$ were of middle class and only $3.3 \%$ were of upper class. Regarding education, around one fifth of the injured people were illiterate and $37 \%$ studied up to primary level, only $2.3 \%$ were graduates. Most common occupation among 
the subjects suffered injury were student (20.4\%), house wife $(16.8 \%)$, skilled laborer $(13.8 \%)$, farmer $(10.7 \%)$ and unskilled laborer $(8.3 \%)$.

The mechanism of injury of $30 \%$ subjects were road accident, of $29.5 \%$ subjects was slip, trip or fall, of $17.9 \%$ victims' mechanism of injury was collision with person or object. Around $10 \%$ had deep cut, $1.4 \%$ had superficial cut, and $3.3 \%$ had other injuries including burn. Among others 1.7\% suffered electrocution, $0.7 \%$ was drowned, $0.9 \%$ was attacked by animal and $1.2 \%$ were bitten by animal or stung by insects. (Figure 1)

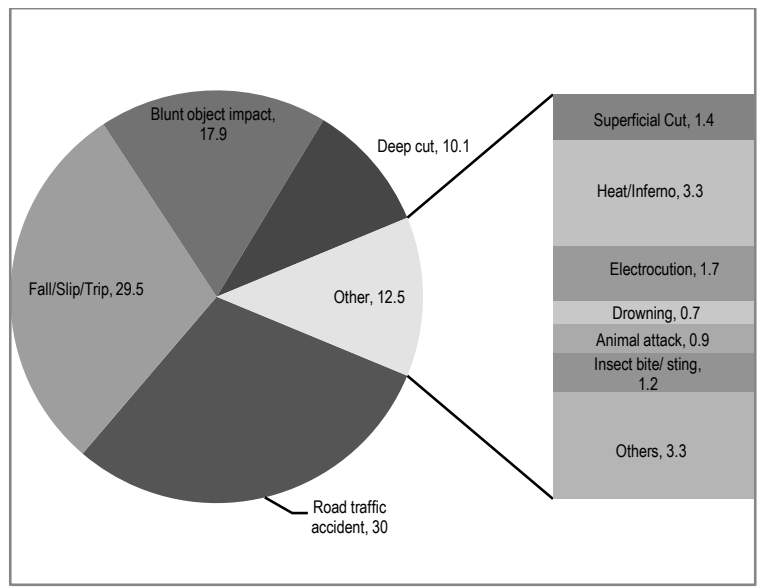

Fig.1: Mechanism of Injury in percentage

Regarding circumstances of injury, most people suffered injury while working or travelling to or from the work place, $16 \%$ were injured while engaging in sports, 9.2\% were injured while not working and $8.7 \%$ were injured during travelling. Among those who suffered injury while travelling, $15.7 \%$ were pedestrian. Among those who were on board, $10.2 \%$ were riding bicycle, $19.7 \%$ were riding on other non motorized vehicle, $13.4 \%$ were riding motor cycle, $17.3 \%$ were riding pick up or van, $10.2 \%$ were riding bus. Of subjects who suffered injury while riding a vehicle, around half $(49.5 \%)$ were driver $41.1 \%$ were passenger and $7.5 \%$ were helper.

Most of the injury occurs during the daytime. In our study we found peak hour of injury from 10 am to 6 pm $(76.7 \%)$. Followed by $7 \mathrm{pm}$ to $8 \mathrm{pm}(7.6 \%)$ (Figure 2)

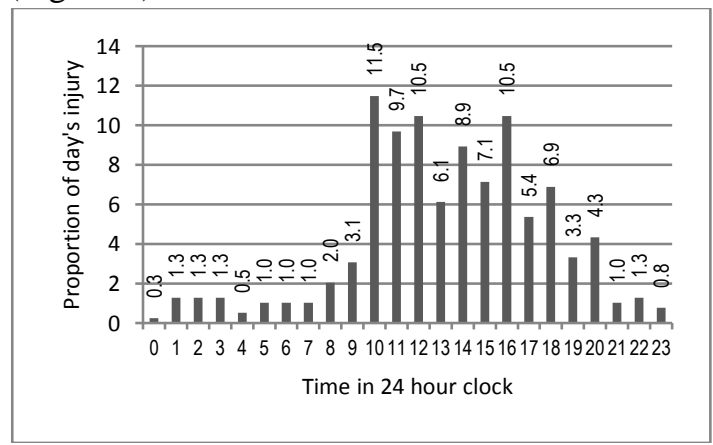

Fig. 2: Timing of injury occurrence
Most frequent types among the injuries were sprain, ache or muscle pull (29.6\%), cut (32.4\%) and fracture of bone $(21.7 \%)$. Among the others bruise or laceration, burn, head injury, organ system injury were notable. Both the extremities together constitute more than $70 \%$ of the reported injury. Besides extremities most frequently injured part of the bodies were head $(15.2 \%)$, face $(9.1 \%)$ chest (7.2\%) spinal cord (5.6\%). Among others eye, teeth and abdomen were also reported. (Figure 3 ).

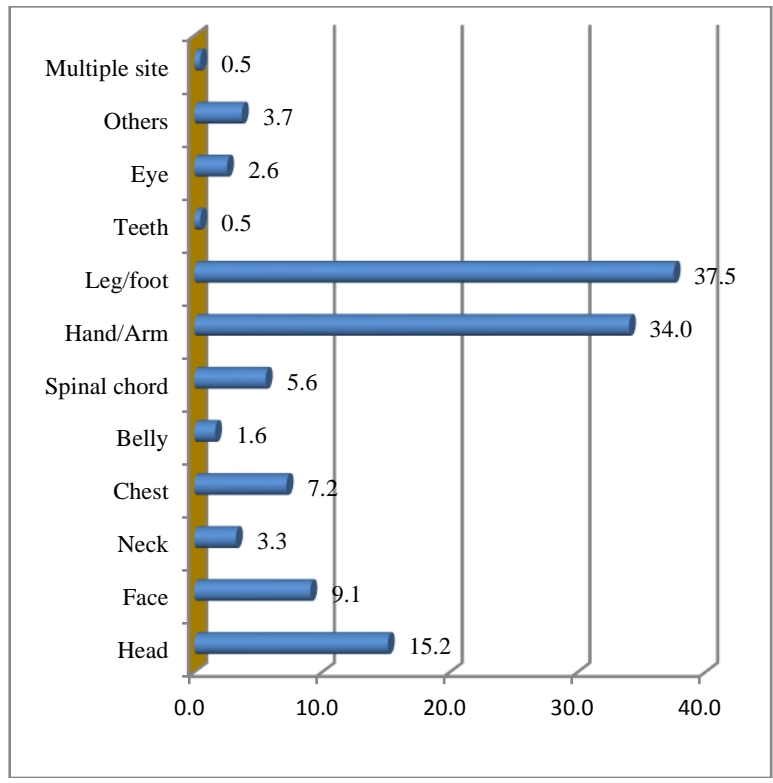

Fig. 3: Part of body injured

Out of 429 injuries around $60 \%$ were of grade I that is the injury hampered at least one day of normal activity, $37.8 \%$ injury were of grade II as these injury required hospital admission, or specific surgical or orthopedic intervention. Around 2.6\% of the injuries were severe enough to be regarded as grade III Injury, as these Injuries resulted in permanent disability or loss of any body part or organ. Six of the people died and were graded as IV.

Treatment seeking for Injury: Out of 429 Injuries, in $62.5 \%$ occasion people received first aid, and $97.2 \%$ received any form of treatment, $34.1 \%$ required hospital admission. In the health facility $65 \%$ were treated at outpatient department, $29.2 \%$ were admitted and $4.6 \%$ were referred to higher level referral facility. Time elapsed between occurrence of injury and time of seeking treatment is an important predictor of treatment outcome of injury. Of the 429 occasions around $58.7 \%$ sought treatment with in one hour, $21.1 \%$ reported between two to four hours, $3.9 \%$ reported between five to eight hours, 3,6\% reported between 9-12 hours. Around 5.6\% reported between 13-16 hours and another $7 \%$ were even late. Majority of the people sought treatment from village doctor or drug shop, $22.6 \%$ went to upazilla health complex, $10.7 \%$ 
went to private hospital, $8.4 \%$ went to district or medical college hospital and $2.1 \%$ had to go to a specialized hospital. Among other options 5.4\% went to community clinics, $3.7 \%$ went to union sub centre and in $2.6 \%$ cases service were brought to home. After injury $39.9 \%$ of the victims were brought to health facility by non motorized vehicle,
$42 \%$ victims were brought with motorized vehicle other than ambulance, only $4.1 \%$ could afford ambulance. Among the injured only $19.2 \%$ escaped any physical consequence, $27.2 \%$ suffered from decrease in work capacity, $48.1 \%$ developed temporary disability, $3.8 \%$ developed permanent disability, and $1.2 \%$ suffered disfiguration.

Table I: Pattern of Injury in relation with age \& sex

\begin{tabular}{|c|c|c|c|c|c|c|c|c|c|}
\hline & $\begin{array}{l}\text { Road accident } \\
\text { (115) }\end{array}$ & $\begin{array}{c}\text { Fall } \\
(113)\end{array}$ & $\begin{array}{c}\text { Struck by } \\
\text { object }(74)\end{array}$ & $\begin{array}{l}\text { Cut } \\
(45)\end{array}$ & $\begin{array}{l}\text { Burn } \\
(20)\end{array}$ & $\begin{array}{l}\text { Drowning } \\
\text { (3) }\end{array}$ & $\begin{array}{c}\text { Animal } \\
\text { bite/sting (8) }\end{array}$ & $\begin{array}{c}\text { Others } \\
\text { (14) }\end{array}$ & Total (392) \\
\hline \multicolumn{10}{|l|}{ Age in yrs. } \\
\hline $1-18$ & $17(15.3)$ & $44(39.7)$ & $17(15.3)$ & $16(14.4)$ & $10(9.0)$ & $1(0.9)$ & $4(3.6)$ & $2(1.8)$ & 111(100) \\
\hline $19-39$ & $56(36.6)$ & $29(18.8)$ & $33(21.4)$ & $22(14.3)$ & $5(3.2)$ & $1(0.6)$ & $1(0.6)$ & $7(4.5)$ & $154(100)$ \\
\hline $40-59$ & $32(34.5)$ & $25(26.8)$ & $19(20.4)$ & $6(6.5)$ & $5(5.4)$ & $1(1.0)$ & $2(2.2)$ & $3(3.2)$ & $93(100)$ \\
\hline$\geq 60$ & $10(29.6)$ & $15(44.1)$ & $5(14.7)$ & $1(2.9)$ & $0(0)$ & $0(0)$ & $1(2.9)$ & $2(5.8)$ & $34(100)$ \\
\hline \multicolumn{10}{|l|}{ Sex } \\
\hline Male & $100(34.9)$ & $73(25.6)$ & $52(18.1)$ & $32(11.1)$ & 11(3.8) & $2(0.6)$ & $5(1.7)$ & $12(4.2)$ & $287(100)$ \\
\hline Female & $15(14.2)$ & $40(38.3)$ & $22(20.9)$ & $13(12.4)$ & $9(8.6)$ & $1(0.9)$ & $3(2.8)$ & $2(1.9)$ & $105(100)$ \\
\hline
\end{tabular}

Among the injured subjects in preceding year, $92.1 \%$ suffered single injury, $6.4 \%$ suffered 2 injuries and $1.5 \%$ of them suffered 3 injuries. More than $80 \%$ of the incidents leading to injury happened during the day, periods between 8 am to 6 pm (Figure 2). During the day Injury mostly occurs at afternoon. Regarding intent of injury $88.8 \%$ were accidental, $6.8 \%$ were intentional, physical assault in particular. Most commonplace of injury reported were home/yard/garden (36\%). Among other major places where injury took place were roads/highway $(32.9 \%)$, factory building $(9.1 \%)$ and crop field $(4.3 \%)$.

\section{Discussion}

Our study reports one death in every 1000 population in one year due to injury. Crude prevalence of injury is 62.7 per 1000 population in a year which is much less than a study in Panjab where an incidence of injury was found to be 116 per 1000 population in a year and much less from a study conducted in Bangladesh which was 311 per 1000 population in a year. ${ }^{6}$ Recently in Pondicherry, also overall, the prevalence of all injury among all age groups was reported to be higher than 306 per 1000 population in last one year. ${ }^{3}$ A remote typical in a village such as Bairag, where mechanized transport system and mechanical production facility are less, which significantly results in a less number of RTA and other related injuries in the area.

Injury was mediated mostly by people of active age group (10-59 years) and around three fourth of them $(73 \%)$ were male. A possible explanation may be that men spend more time on the roads. Besides male are more prone to high risk behaviors or unsafe road practices. $^{7}$ Several studies were conducted to explore the injury epidemiology around the globe. ${ }^{8-10}$ However extreme difficulty lies in relating the findings due to heterogeneity of measurement methods and statistical operations. The Pondicherry study that share relatively similar socio-demographic profile reported similar high prevalence for those 18 years and older and among men. ${ }^{3}$ The road traffic injuries were high among males and above 18 years of age. ${ }^{3}$ About $99.2 \%$ of the reported injuries were accidental and majority $(58.2 \%)$ went to government doctor for treatment.

Similar to the distribution of the catchment population, majority $(55.6 \%)$ were of lower class. Regarding education, around one fifth of the injured people were illiterate and $37 \%$ studied up to primary level and $24 \%$ studied up to secondary level. Similar finding was found in other studies. ${ }^{11-}$ 12 It was observed that more people with lower levels of education were involved in injuries. However, this relationship between education and injury may not be causal. Most prevalent occupation among the subjects lasting injury were, student $(20.4 \%)$, house wife $(16.8 \%)$, skilled labor $(13.8 \%)$ and unskilled labor $(8.3 \%)$.

Socio-economic status has been documented to be an important determinant of injury, although the effect depends on the socio-economic indicator, cause and severity of injury. ${ }^{13}$ Moshiro et al. found no significant relationship between poverty and nonfatal injuries. ${ }^{12}$ This is consistent with findings from other studies as well. ${ }^{14,15}$ Contrary to this, in our study more persons with primary and secondary education suffered injury than those with no formal education. A previous study done in India also reported similar finding. ${ }^{16}$

Injury at the workplace that involved mainly cutting or crushing was found more frequently in this study, which may be due to the fact that rural people of Bangladesh work in agriculture with unprotected conventional equipment. ${ }^{6}$ In our study 
farmers constitutes $10.7 \%$ of the injured subjects. Agro-based injury in our study is relatively higher than other reported studies in the region. A study in rural Haryana reported $8 \%$ prevalence of agriculture related injuries. ${ }^{8}$

Prevalence of repeated injury is around eight percent. Occurrence of repeated injury suggests the persistent reckless behavior or persistence of risk element in the surrounding, which has significant policy implication as there is potential for possible initiative of risk reduction. Time of the injury occurrence was one of the factors worth discussing as, out of every five of the incident leading to injury occurred during the day, which is the usual work hour. During the day injury mostly occurs at afternoon. In the present study, the peak time for injury was 10 am to $6 \mathrm{pm}(76.6 \%)$, followed by 7 $\mathrm{pm}$ to $8 \mathrm{pm}(7.6 \%)$. Similar finding has been observed by Ghimire et al. in Nepal. ${ }^{11}$ Morning hours are the busiest due to schools, offices, factories and business places and were more prone to injuries. Afternoon hours are the busiest times as people return home after finishing their work at this time. During this period, children usually go to play and hence they were more exposed to different types of injuries. Only (6.1\%) of people got major injuries at 7 am to $8 \mathrm{am}$, it may be because at that time people are at home and roads are also not so busy, hence there is less chances of injuries at that time. Study by Roudsari et al. also reported high prevalence of injury at day time; they reported peak prevalence at 12:00 to 18:00 hour. $^{7}$

In the rural area most common place of injury reported was home, yard or garden. Among other major places where injury took place were roads and highway. Factory and crop fields showed less injury, probably due to use of less mechanized techniques. Regarding circumstances of injury, most people suffered injury while working or travelling to or from the work place, sixteen percent were injured while on sports, around nine percent each were injured while not working and during travel respectively. The study from the Nepal, reported a higher numbers of minor injuries occurring at home $(55.6 \%)$, followed by road $(21.6 \%)$ and recreation areas including sports (20.0\%). But there most major injury occurred on road. ${ }^{13}$ Most frequent types among the injuries were sprain, ache or muscle pull $(29.6 \%)$, Fracture of bone $(21.7 \%)$, Cut (32.4\%). Cuts and falls contributed significantly among children aged 5 to 14 years with farm work; play was the main contributing factor in the rural area. As emphasized in other studies, there is a need for safe playground for children. Among the injured only one fifth escaped any physical consequence.
The present community-based research describes the local situation of injuries in different age groups which can be useful for development of injury surveillance and prevention. Borse et al. recommended that developing countries should take initiative in not only reducing the burden of unintentional injuries by appropriate research but also publishing such work and contribute to the global pool of knowledge. ${ }^{17}$

The limitations of the present study should be kept in mind. It was a small scale study based on a nonprobability sample. One of the most significant limitations of community-based surveys is rooted in their reliance on self-reporting by respondents. The accuracy of respondents' answers on the occurrence of injury events or the duration of the resultant disability cannot be independently verified. The household head or in their absence a representative was taken as a proxy respondent for all other members with the assumption that he/she would better recall injuries for all the other family members. Intentional injuries such as assaults and domestic violence are probably underreported since they would not be adequately captured in such a survey. This may lead to injury rates being underestimated. In this study, a clinical injury severity assessment was not possible. Disability days were used instead as a measure of severity of injury. Despite its limitations, this study has generated information that could be useful for targeted prevention at the local level.

The 'Global Burden of Disease Study' estimates that $10 \%$ of global deaths are due to injuries and that if current trends persist; this burden will greatly increase in the next 20 years. $^{18}$ Members of younger age groups are the most common victims of injury, which is also a very striking feature, since injury may cause disability for life. The leading causative mechanism of minor injuries was cut/stab and fall. The injuries related to lifestyle profession and RTA is the commonest burden revealed in the study sample. Promotion of safety at work and education for protection at work and safe driving can prevent the major socio-economic loss to the family and community at large. This study is an attempt to highlight the extent of ill health due to injury in a developing country's population. A more standardized approach to collection and presentation of injury data would make a growing body of epidemiological research considerably more useful in setting priorities for more detailed research and policy recommendations.

\section{Acknowledgement}

The study received grant from DGHS, Government of Bangladesh. The authors also wish to thank 
Professor Harunur Rashid and Dev Care foundation of Anwara upazilla for their active support during conduction of data collection.

\section{References}

1. The Melbourne Declaration. Third International Conference on Injury Prevention and Control. Melbourne, Australia; 1996 [cited 2014 May 25]. Available from: http://www.who.int/violence_injur y_prevention/resources/res25/en/

2. Sethi D, Habibula S, McGee K, Peden M, Bennett S, Hyder AA, et al. (eds): World Health Organization. Guidelines for conducting community surveys on injuries and violence; 2004 [cited 2014 May 25] Available from http://www.informaworld.com /index/713817814.pdf

3. Kalaiselvan G, Dongre AR, Mahalakshmy T. Epidemiology of injury in rural Pondicherry, India. J Inj Violence Res. 2011; 3(2): 62-7.

4. Child injury prevention in the South-East Asia region World Health Organization; 2008 [cited 2014 May 25] Available from: http://www.who.int/violence_injury_ prevention/child/injury/world_report/CIP_SEARO.pdf.

5. "The challenge of lowering the burden of injury globally and in the WHO Eastern Mediterranean Region; 2009 [cited 2014 May 25]. Available from: http://www.un.org/en/ecosoc/newfunct/pdf/discussion $\% 20$ paper\%20on\%20injuries $\% 20-\% 205 \% 20$ may\% 202009.pdf

6. Rahman F, Andersson R, Svanström L. Health Impact of Injuries: A Population-Based Epidemiological Investigation in a Local Community of Bangladesh. Journal of Safety Research, 1998; 29(4):213-22

7. Roudsari BS, Sharzei K, Zargar M: Sex and age distribution in transport-related injuries in Tehran. Accident Analysis and Prevention 2004, 36:391-98.
8. Garg N, Hyder AA. Road traffic injuries in India: a review of the literature. Scand J Public Health. 2006; 34(1): 100-9.

9. Lamawansa M, Piyathilake A. Incidence of physical injuries in rural community in Sri Lanka: result of the first community survey in Sri Lanka. Indian J Community Med. 2008; 33(4):238-42.

10. Kobusingye $\mathrm{O}$, Guwatudde $\mathrm{D}$, Lett R. Injury patterns in rural and urban Uganda. Inj Prev 2001; 7:46-50.

11. Ghimire A, Nagesh S, Jha N, Niraula SR, Devkota S. An epidemiological study of injury among urban population. Kathmandu University Medical Journal 2009; 7(4), 402-7

12. Moshiro C, Heuch I, Astrøm AN, Setel P, Hemed Y and Kvale Gunnar. Injury morbidity in an urban and a rural area in Tanzania: an epidemiological survey BMC Public Health 2005; 5:11

13. Cubbin C, LeClere FB, Smith GS: Socioeconomic status and the occurrence of fatal and nonfatal injury in the United States. American Journal of Public Health 2000, 90:70-7.

14. Kelly SM, Miles-Doan R: Social inequality and injuries: do morbidity patterns differ from mortality? Social Science and Medicine 1997; 44:63-70.

15. Addor V, Santos-Eggimann B: Population-based incidence of injuries among preschoolers. European Journal of Pediatrics 1996; 155:130-135.

16. Verma PK, Tewari KN. An epidemiologic study of injuries in the area of municipal corporation of Delhi, World Health Organization, Regional Office for SouthEast Asia; 2003 [cited 2014 May 25]. Available from: http://apps.searo.who.int/pds_docs/B0031.pdf

17. Borse NN, Hyder AA. Call for more research on injury from the developing world: Results of a bibliometric analysis. Indian J Med Res 2009; 129:321-26.

18. Murray CJL, Lopez AD. Mortality by cause for eight regions of the world: Global Burden of Disease Study. Lancet1997; 349:1269-76. 